Clemson University

TigerPrints

Publications

Languages

6-6-2019

\title{
Faculty Satisfaction with Start-up Packages: Gender Differences in a Public University in the Southeastern U.S.
}

\author{
Alena Höfrová \\ Czech University of Life Sciences \\ Arelis Moore de Peralta \\ Clemson University, ared@clemson.edu
}

Follow this and additional works at: https://tigerprints.clemson.edu/languages_pubs

Part of the Education Commons

\section{Recommended Citation}

Höfrová, A. \& Moore De Peralta, A. (2019). Faculty satisfaction with start-up packages: gender differences in a public university in the southeastern U.S. Proceedings of the 16th International Conference Efficiency and Responsibility in Education 2019, 68 - 75. Prague, Czech Republic, EU.

This Conference Proceeding is brought to you for free and open access by the Languages at TigerPrints. It has been accepted for inclusion in Publications by an authorized administrator of TigerPrints. For more information, please contact kokeefe@clemson.edu. 


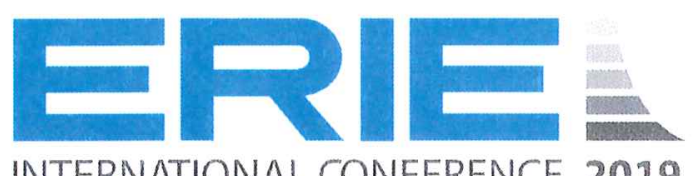

INTERNATIONAL CONFERENCE 2019

\section{PROCEEDINGS}

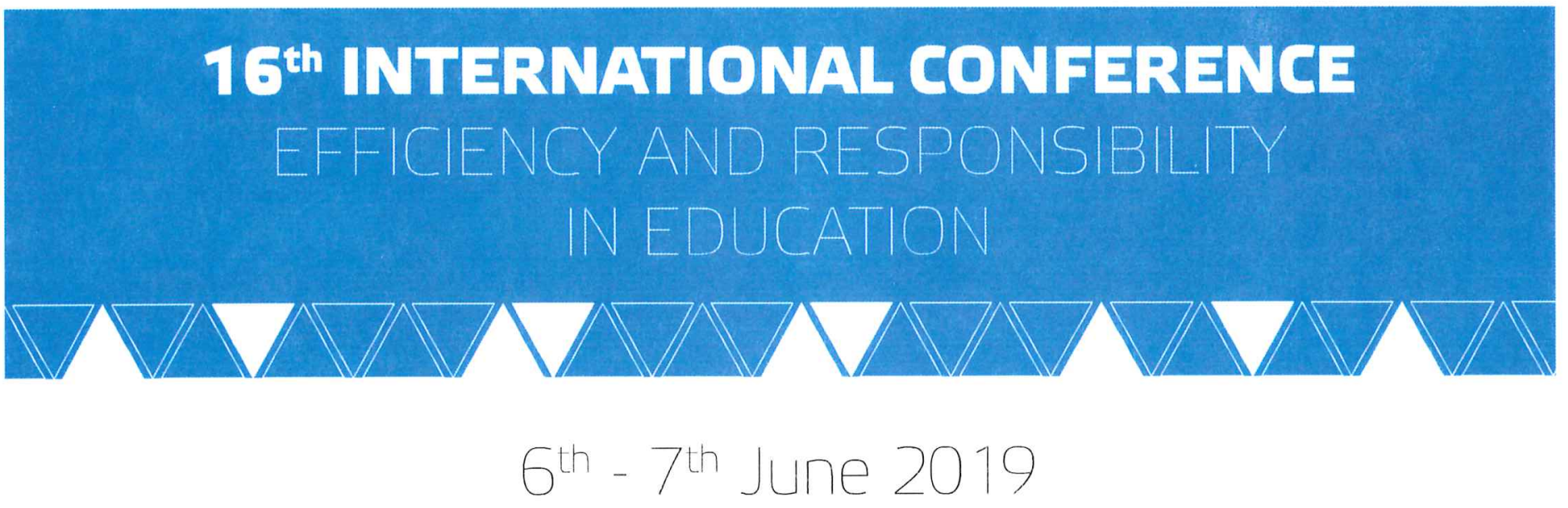

(0). Faculty of Economics and Management 


\title{
FACULTY SATISFACTION WITH START-UP PACKAGES: GENDER DIFFERENCES IN A PUBLIC UNIVERSITY \\ IN THE SOUTHEASTERN U.S.
}

\author{
Alena Höfrová, ${ }^{2}$ Arelis Moore de Peralta
}

Department of Youth, Family and Community Studies, College of Behavioral, Social and Health

Sciences, Clemson University, South Carolina, United States of America, ahofroverclemsonedu

Department of Psychology, Faculty of Economics and Management, Czech Unversity of Life Sciences Prague, Czech Republic

aepartments of Languages, and Youth, Family and Community Studies, Clemson University, South Carolina, United States of America

\section{ABSTRACT}

Start-up packages are time limited financial and material resources offered by universities to incoming faculty during the hiring process. Previous research findings on gender equity within the start-up packages are mixed. Therefore, this study is exanimating the role of gender on the content of start-up packages, satisfaction with the packages, university honoring startup packages, and contribution of start-up packages to faculty professional development. Data corresponds to a Start-Up Package Satisfaction Survey of faculty at all ranks $(\mathrm{N}=96)$ administered in an American Southeastern public research university in 2018. Results from this study indicated that there are significant differences between male and female faculty in the overall satisfaction with the start-up packages, and in faculty perception on university honoring their start-up packages offers. Specifically, female faculty were less satisfied with start-up packages and were more likely to perceive that the university did not honor their startup packages.

\section{KEYWORDS}

Benefit satisfaction, faculty professional development, gender equity, hiring process, start-up packages

\section{INTRODUCTION}

Start-up packages can be defined as time limited financial and material resources offered by universities to new faculty during the hiring process (Hamann, 2013). Universities are competing with each other to recruit the best faculty by providing attractive start-up packages (Callie and Cheslock, 2008; Committee on Partnership for Emerging Research Institutions, 2009; Ehrenberg, Rizzo, and Condie, 2003). Start-up packages should help faculty to establish their research projects until they are able to secure further funding (Rancourt, 2010). Therefore, it is essential that new faculty obtain benefits that help them to be successful and productive (Bralower, 2005). The negotiation of start-up packages is dependent on the administrative structure of the college; the start-up packages are usually negotiated with the department chair or with both the dean of college and the department chair (Reis, 1997). The duration of startup packages is usually a few years (one to two years), and the specific number of years for which the package is available to the faculty should be negotiated during the interview as well (Bralower, 2005; Hamann, 2013).

Hiring processes are influenced by gender inequalities within organizations (Stamarski and Son Hing, 2015). Research has shown that female faculty perceive more gender discrimination during hiring processes within university settings and are less satisfied with the overall hiring processes than male faculty (Faculty of Arts and Sciences Gender Equity Committee, 2002; 
Langley et al., 2013). In addition, female faculty receive less benefits in their start-up packages and are less likely to perceive that departments did the best to obtain resources for them than male faculty (Langley et al., 2013; Van Delinder et al., 2015). Similarly, Layne (2006) showed that female faculty received less average value of start-up packages at all academic ranks at the College of Engineering and the College of Science at Virginia Tech University in the academic year 2005/2006. Analysis conducted by the University of Virginia (2014) showed that male faculty received a higher mean value of start-up packages than female faculty in Science, Technology, Engineering, Mathematics disciplines (STEM) and Social and Behavioral Sciences disciplines (SBS) at the University of Virginia; nonetheless, the mean difference was not statistically significant. However, in the academic year 2004/2005, female faculty received higher average value of start-up packages at all academic ranks at the College of Engineering at Virginia Tech University (Layne, 2005). In addition, the National Research Council (2010) found that start-up packages were comparable between female and male faculty. These findings are in accordance with an experiment conducted by Allen, Smith, and Ransdell (2019) which showed that candidates' gender does not influence the hiring evaluator's decision-making process with regard to the amount of salary, start-up funding, or research space allocation. Therefore, findings on gender differences within the content of start-up packages are mixed.

Overall, female faculty have been found to be less satisfied with their jobs at universities than male faculty (Callister, 2006). Specifically, Rosser (2004) found that female faculty were less satisfied with the quality of benefits and their salary level than male faculty. Additionally, female faculty have been found to be less satisfied with their start-up packages at the time of hire at the University of Southern Maine (Langley et al., 2013). Gender differences within university settings have also been found in the perception of university fair treatment. Female faculty perceive that they are treated less fairly at the institutional level as well as by their superiors than male faculty (Holliday et al., 2015; Jagsi et al., 2017; Martin, 2011). Unfair treatment can also be seen in unfair workload distribution and its effect on faculty professional development. Female faculty were more likely to have less teaching free periods than male faculty; therefore, they had less time to conduct research and to work on publications (Kjeldal, Rindfleish, and Sheridan, 2005).

This paper presents findings of a study that explored the following research question: What is the role of gender on obtained benefits in start-up packages, satisfaction with start-up packages, perception of university honored start-up packages, and contribution of start-up packages to professional development? In addition, the following null hypotheses were tested.

Hypothesis $0_{1}$. Number of obtained benefits does not significantly differ by faculty gender.

Hypothesis $0_{2}$. Satisfaction with benefits at the time of hire does not significantly differ by faculty gender.

Hypothesis $0_{3}$. Satisfaction with benefits at the time of the study does not significantly differ by faculty gender.

Hypothesis $0_{4}$. Satisfaction with the overall start-up packages does not significantly differ by faculty gender.

Hypothesis $0_{5}$. Faculty perception if the university honored the start-up packages does not significantly differ by faculty gender.

Hypothesis $0_{6}$. Contribution of start-up packages to faculty professional development does not significantly differ by faculty gender.

Following, methods and procedures used to conduct the study will be explained including data collection, participants, measures, and data analysis. Further, results are presented, followed by a discussion of the findings, conclusions, and recommendations. 


\section{Materials and Methods}

\section{Data Collection}

The current study utilizes data from the Start-Up Package Satisfaction Survey administered in a Southeastern university from April 2018 to June 2018. The survey focused on faculty attitudes towards start-up package offers, negotiation, satisfaction, and obtained benefits. Prior to data collection, Institutional Review Board approval was obtained. Tenure-track and tenured faculty $(\mathrm{N}=989)$ at a research public university in the Southeastern U.S. received an email, and further a reminder, to participate in the survey using a web-based Qualtrics platform. One hundred and twenty-seven opted for completing the survey; the response rate was $13 \%$. Participants read and signed an informed consent by agreeing to complete the survey.

\section{Participants}

Participants who were considered as the sample for this study were participants who obtained a start-up package and also chose to respond to the demographic question about their gender by indicating their gender as male or female. Those who chose "I prefer not to answer", "I don't identify myself with any of the above", or did not answer this question were filtered out of the analyses. To secure participants' confidentiality, demographics questions were voluntary. This study analyzes data from a sample of $(n=96)$ tenure and tenure-track faculty were $51 \%(n=49)$ males and $49 \%(n=47)$ females.

\section{Measures}

The number of overall obtained benefits was calculated based on participants' responses to 34 items from the survey where respondents indicated whether one of each 17 specific benefits were offered to them, or not offered to them, and also if they obtained the benefit through negotiation of their start-up package. The benefits were classified in four groups (i.e., terms of employment, equipment, moving expenses, and other benefits). The response options were "yes", "no", and "I don't know" for 17 items assessing if the benefit was offered to them and "yes", "no", and "N/A" for 17 questions asking if participants negotiated for the specific benefit. The items were recoded as " 0 " if they did not obtain a benefit through offer or through negotiation and if they did not remember or did not answer the question; and as " 1 " if they obtained the specific benefit regardless if it was offered to them or if they negotiated for the specific benefit. The final number of obtained benefits was a sum of the recoded 17 variables.

The variable "number of benefits satisfied with at the time of hire" was assessed by summing responses of two sets of questions in regard to 17 benefits. The first set of questions asked if participants were satisfied at the time of hire with the specific benefit which was offered to them; the response options were "yes" and "no. The second set of questions asked if respondents were satisfied at the time of hire with benefits which they negotiated; the response options were "yes", "no", and "N/A". The variables were recoded as " 0 " if participants were not satisfied with a specific benefit offered or negotiated, when they did not respond, or their response was "N/A"; the variables were recorded as " 1 " if participants were satisfied with the specific offered or negotiated benefit. The final variable of number of benefits satisfied with at the time of hire is a sum of the 17 recoded items.

The variable "number of benefits satisfied at the time of the study" was computed by summing the two sets of questions across 17 benefits. In the first set of questions, participants indicated if they are now satisfied with the benefit which was offered to them; the response options were "yes", "no", and "N/A". The second set of the questions asked if respondents are now satisfied with the benefit which they negotiated for; the response options were "yes", "no", and "N/A". 
The variables were recoded as "0" if participants were not satisfied with the specific offer or negotiated benefit and when they did not respond, or their response was "N/A"; the variables were recorded as " 1 " if participants were satisfied with the specific offered or negotiated benefit. The final variable of number of benefits satisfied with at the time of the study is a sum of the 17 recoded items.

Satisfaction with the overall start-up packages was measured with two items. Participants responded to items rated on a satisfaction scale from 1 (extremely dissatisfied) to 5 (extremely satisfied). The estimated Cronbach's alfa of this scale was .84. Questions included asked about satisfaction with the original start-up offer and about satisfaction with the result of negotiation for the start-up package.

Honored start-up packages were measured by a single item asking to rate the level of agreement if the university honored all aspects of the start-up package on an agreement scale of 1 (strongly disagree) to 5 (strongly agree).

The variable "contribution to professional development" was a single-item measure on an agreement response scale ranging from 1 (strongly disagree) to 5 (strongly agree). The question asked participants to rate the level of agreement that the start-up package helped or contributed to faculty professional development.

\section{Data Analysis}

Collected data were analyzed using IBM SPSS Statistics Version 24.0. Data analyses included descriptive statistics, analysis of variance (ANOVA), and correlation analysis. Descriptive statistics were used for participant demographics. Univariate ANOVA was conducted to compare the means of major study variables to determine if statistically significant differences existed based on gender (Tabachnick and Fidell, 2013). Levene's test for equality of variances was used to test the homogeneity of variance assumption. Pearson correlation matrix was calculated to further examine the relationships between study variables.

\section{RESULTS}

Of the 96 faculty who completed the survey, 51\% were males, most were self-identified as White non-Hispanic (80.2\%), were in the Assistant professor rank (42.7\%), and were in a STEM discipline $(50 \%)$. A summary of the demographic information of the participants can be found in Table 1.

Descriptive statistics were calculated for the number of overall obtained benefits in start-up packages, satisfaction with the benefits at the time of hire, satisfaction with benefits at, overall satisfaction with start-up packages, packages honored by university, and contribution of start-up packages to faculty professional development. The mean value of the number of obtained benefits in the start-up packages was $6.94(S D=3.06)$. In addition, results revealed that faculty in the sample generally expressed that they were overall satisfied with their start-up packages $(M=2.83$, $S D=1.26)$, the university honored their packages $(M=3.60, S D=1.45)$, and that their start-up packages contributed to their professional development $(M=3.72, S D=1.51)$. A summary of descriptive statistics of major study variables are shown in Table 2.

Results of bivariate correlation analysis of the study variables is presented in Table 3 . The Correlation matrix shows that number of overall obtained benefits in start-up packages, satisfaction with the benefits at the time of hire, satisfaction with benefits at the time of the study, overall satisfaction with start-up packages, packages honored by university, and contribution of start-up packages to faculty professional development were significantly and positively associated with each other. 


\begin{tabular}{|c|c|c|c|}
\hline Variable & Categories & $n$ & $\%$ \\
\hline \multirow{2}{*}{ Gender } & Male & 49 & 51.0 \\
\hline & Female & 47 & 49.0 \\
\hline \multirow{6}{*}{ Race and/or ethnicity } & Asian, Asian-American, or Pacific Islander & 5 & 5.2 \\
\hline & White (пon-Hispanic) & 77 & 80.2 \\
\hline & Black or African-American & 3 & 3.1 \\
\hline & Hispanic or Latino & 5 & 5.2 \\
\hline & I prefer not to answer & 4 & 4.2 \\
\hline & Other & 1 & 1.0 \\
\hline \multirow{5}{*}{ Current academic rank } & Professor & 26 & 27.1 \\
\hline & Associate Professor & 25 & 26.0 \\
\hline & Assistant Professor & 41 & 42.7 \\
\hline & I prefer not to answer & 4 & 4.2 \\
\hline & Other & & \\
\hline \multirow{5}{*}{ Disciplines $*$} & STEM & 48 & 50 \\
\hline & SBE & 11 & 11.5 \\
\hline & Noח-5\&E & 4 & 4.2 \\
\hline & Professional/Other & 4 & 4.2 \\
\hline & Other & 21 & 21.9 \\
\hline
\end{tabular}

* Categories of disciplines were made based on the U.S. National Science Foundation's requirement for data reporting; STEM (science, technology, engineering, and mathematics), SBE (social, behavioral, and economic sciences), Non-S\&E (non-science and engineering), Professional/Other (e.g. communications, parks/recreation/leisure/fitness).

Table 1:The demographics of the sample

\begin{tabular}{lccccr}
\multicolumn{1}{c}{ Variable } & Min & Max & Mean & SD & Skew \\
\hline Number of obtained benefits & 0 & 14 & 6.94 & 3.06 & .30 \\
\hline Satisfaction with the benefits - time of hire & 0 & 14 & 5.47 & 3.13 & .68 \\
\hline Satisfaction with the benefits - time of study & 0 & 12 & 3.77 & 3.10 & .83 \\
\hline Overall satisfaction with the packages & 1 & 5 & 2.83 & 1.26 & -.01 \\
\hline Honored packages & 1 & 5 & 3.60 & 1.45 & -.56 \\
\hline Contribution to professional development & 1 & 5 & 3.72 & 1.51 & -.83 \\
\hline
\end{tabular}

Table 2: Descriptive statistics of study variables

\begin{tabular}{|c|c|c|c|c|c|c|}
\hline Variable & 1 & 2 & 3 & 4 & 5 & 6 \\
\hline 1. Number of obtained benefits & - & $84^{* * *}$ & $70^{* * *}$ & $.38^{* * *}$ & $44^{* * *}$ & $52^{* * *}$ \\
\hline 2. Satisfaction with the benefits - time of hire & & - & $78^{* * *}$ & $.52^{* * *}$ & $.52^{* * * *}$ & $55^{* * *}$ \\
\hline 3. Satisfaction with the benefits - time of study & & & - & $41^{* * *}$ & $50^{* * *}$ & $43^{* * * *}$ \\
\hline 4. Overall satısfaction with the packages & & & & - & $48^{* * *}$ & $74^{* * *}$ \\
\hline 5. Honored packages & & & & & - & $.59^{* * *}$ \\
\hline 6. Contribution to professional development & & & & & & - \\
\hline
\end{tabular}

Table 3:Pearson's correlation coefficients between variables

Levene's test verified the equality of variances in the samples, in other words, the homogeneity of variance assumption was not violated $(\mathrm{p}>.05)$. There was one case of missing data in variables included in the analysis; this one case of missing data was handled with pairwise deletion. The results from univariate ANOVA that exanimated the gender mean differences in the start-up packages are presented in Table 3. Female faculty reported lower number of obtained benefits in the start-up packages $(M=6.45 ; S D=3.03)$ than male faculty $(M=7.50 ; S D=3.02)$. However, the difference 
in the number of obtained benefits in the start-up packages between female and male faculty was not statistically significant, $F(1,93)=2.88, p=.093, \eta^{2}=.030$. Therefore, Hypothesis 0 , was not rejected. Female faculty were less satisfied with the benefits at the time of hire $(M=4.91 ; S D=2.88)$ than male faculty $(M=6.10 ; S D=3.25)$. Nevertheless, the mean difference between female and male faculty satisfaction with the benefits at time of hire was not significant, $F(1,93)=3.56, p=.062, \eta^{2}=.037$. Thus, Hypothesis $0_{2}$ was not rejected. Female faculty were currently less satisfied with the benefits that they obtained in their start-up packages $(M=3.32 ; S D=2.94)$ than male faculty $(M=4.23 ; S D=$ 3.22). Notwithstanding, the mean difference between female and male faculty current satisfaction with the benefits obtained in the start-up packages was not significant, $F(1,93)=2.06, p=.154, \eta^{2}=.022$. Hypothesis $0_{3}$ was not therefore rejected. Female faculty reported lower levels of overall satisfaction with the start-up packages $(M=2.49 ; S D=1.16)$ than male faculty $(M=3.21 ; S D=1.25)$. There was a significant mean difference in the overall satisfaction with start-up packages between female and male faculty, $F(1,93)=8.45, p<.01, \eta^{2}=.083$. Hence, Hypothesis $0_{4}$ was rejected. Female faculty expressed lower levels of honored start-up packages by university $(M=3.28 ; S D=1.49)$ than male faculty $(M$ $=3.92 ; S D=1.35$ ). There was a significant difference in the level of honored start-up packages by university between genders, $F(1,93)=4.84, p<.05, \eta^{2}=.049$. Hypothesis $0_{5}$ was rejected. Female faculty perceived that their start-up packages contributed less to their professional development $(M$ $=3.47 ; S D=1.56)$ than male faculty $(M=4.02 ; S D=1.39)$. However, the mean difference between female and male faculty in contribution of the start-up packages to professional development was not significant, $F(1,93)=3.33, p=.071, \eta^{2}=.035$. Therefore, Hypothesis $0_{6}$ was not rejected.

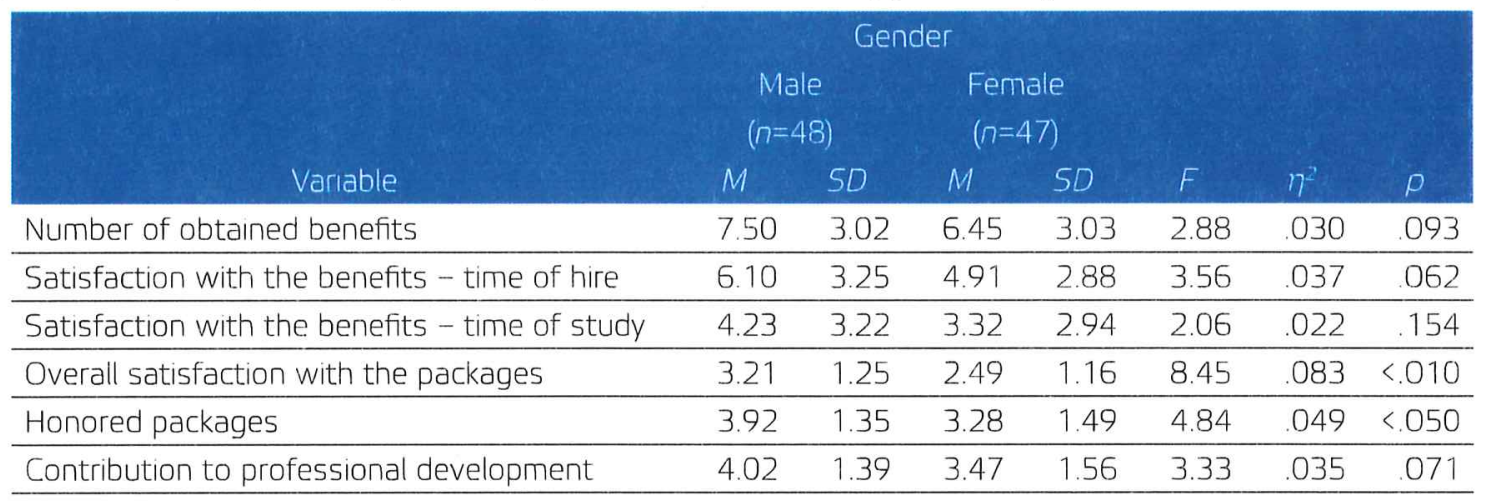

Table 4: Mean differences by gender

\section{Discussion}

Gender inequality can influence hiring processes and faculty careers (Carr et al., 2019; Stamarski and Son Hing, 2015). However, little is known about how gender influences start-up packages within academia and findings about gender differences in start-up packages are mixed. Results from this study indicated that there are significant differences between male and female faculty in the overall satisfaction with the start-up packages and in faculty perception if university honored their start-up packages. Specifically, female faculty were less satisfied with the start-up packages and were more likely to perceive that the university did not honor their start-up packages. These findings are consistent with previous research which showed that female faculty are less satisfied with the overall hiring processes (Langley et al., 2013), and that female faculty are less likely to perceive that the university treats them fairly (Holliday et al., 2015; Martin, 2011). However, the findings are not consistent with the study conducted by Robst, VanGilder, and Polachek (2003) that found that majority of male and female faculty believe that female faculty are treated fairly. The implication for the universities is that they should offer packages that are attractive for new faculty and would satisfy them. In addition, universities should offer only packages which they can deliver to prevent the perception of unfair treatment, especially by female faculty. Even though, in this study, male faculty 
obtained higher number of benefits in their start-up packages, the difference was not statistically significant. Therefore, research which concluded that there are no significant differences between female and male start-up packages was supported (Allen, Smith, and Ransdell, 2019; Layne, 2005; National Research Council, 2010; University of Virginia, 2014). In addition, although there were no significant differences between male and female faculty on the number of obtained benefits in the start-up packages, satisfaction with the packages at the time of hire, satisfaction with the packages at the time of study, and contribution of the start-up packages to the professional development; all the study variables were positively correlated with contribution of the start-up packages to faculty professional development. Future inquiry on these relationships by accounting for a bigger sample size would potentially yield significant results portraying the hypothesized differences in this study.

\section{CONCLUSION}

The present study showed that females are significantly less overall satisfied with start-up packages and start-up packages are significantly less likely to perceive that the university honored their start-up packages. On the other hand, there were no significant differences between female and male faculty in terms of number of obtained benefits in the packages, satisfaction with the benefits at the time of hire, satisfaction with benefits at the time of study, and contribution of the start-up packages to faculty professional development. In addition, the study revealed positive correlation among all study variables. Therefore, future research should examine the directionality of those relationships, by considering a bigger and more diverse sample.

\section{AcknOWLedgements}

The financial support for this work was through the National Science Foundation (HRD-1629934).

\section{REFERENCES}

Allen, J., Smith, J.L. and Ransdell, L.B. (2019) 'Missing or seizing the opportunity? The effect of an opportunity hire on job offers to science faculty candidates', Equality, Diversity and Inclusion: An International Journal, vol. 38, no. 2, pp. 160-177. http:/dx.doi.org/10.1108/EDI-09-2017-0201

Bralower, T. (2005) Negotiating a job offer, [Online], Available: hittps:/serc.carleton.edu NAGTWorkshops/careerprep/jobsearch/Bralower negotiation.html [1 Mar 2019].

Callister, R.R. (2006) 'The impact of gender and department climate on job satisfaction and intentions to quit for faculty in science and engineering fields', The Journal of Technology Transfer, vol. 31, no. 3, pp. 367-375. http:/dx.doi.org/10.1007/s10961-006-7208-y

Callie, T.M. and Cheslock, J.J. (2008) 'The hiring and compensation practices of business school deans', The Review of Higher Education, vol. 32, no. 1, pp. 25-49. littp:/ dx. doi.org/10.1353/the.0.0021 Carr, P.L., Helitzer, D., Freund, K., Westring, A., McGee, R., Campbell, P.B., Wood, C.V. and Villablanca, A. (2019) 'A summary report from the research partnership on Women in Science Careers', Journal of General Internal Medicine, vol. 34, no. 3, pp. 356-362. hittp:/dx.doi.org/10.1007/s $11606-018-4547-y$ Committee on Partnerships for Emerging Research Institutions, National Academy of Engineering, National Research Council (2009) Partnerships for emerging research institutions: Report of a workshop. Washington, D.C: National Academies Press.

Ehrenberg, R. G., Rizzo, M. J. and Condie, S.S. (2003) Start-up costs in American research universities. Cornell University: Working papers, vol. 38), [Online], Available: littp:/digitalcommons.ilr.comell.edu/ workingpapers/38 [1 Mar 2019].

Faculty of Arts and Sciences Gender Equity Committee. (2002) A study of gender equity in the faculty of arts and sciences in New-Brunswick Rutgers university, [Online], Available: http:/sas.rutgers.edu/ documents/reports-and-resolutions/gender-equity-committee-reports/39-executive-summary-genderequity-report/file [3 Mar 2019]. 
Hamann, D.L. (2013) On staff: A practical guide to starting your career in a university music department, US: Oxford University Press.

Holliday, E., Griffith, K., De Castro, R., Stewart, A., Ubel, P. and Jagsi, R. (2015) 'Gender differences in resources and negotiation among highly motivated physician-scientists', Journal of General Internal Medicine, vol. 30, no. 4, pp. 401-407. http://dx.doi.org/10.1007/s11606-014-2988-5

Jagsi, R., Griffith, K.A., Jones, R.D., Stewart, A. and Ubel, P.A. (2017) 'Factors associated with success of clinician-researchers receiving career development awards from the National Institutes of Health: A longitudinal cohort study", Academic Medicine, vol. 92, no. 10, pp. 1429-1439. hitp://dx.doi.org/10.1097/ ACM.0000000000001728

Kjeldal, S.E., Rindfleish, J. and Sheridan, A. (2005) 'Deal-making and rule-breaking: Behind the façade of equity in academia', Gender and Education, vol. 17, no. 4, pp. 431-447. https:/doi-org.libproxy. clemson.edu/10.1080/(09540250500145130

Langley, Turnbaugh, S., Anderson, A., Gibson, J., Lynn, D. and Zollitsch, B. (2013) Advance project: USM faculty work climate survey-preliminary report, [Online], Available: https:/digitalcommons.usm. maine.edu/cgi/viewcontent.cgi?article=1001\&context=women advance [2 Mar 2019].

Layne, P. (2005) AdvanceVT annual report: Year 2: September 2004-June 2005, [Online], Available: https:/vtechworks. lib.vt.edu/bitstream/handle/10919/72154/advancevt annual report_2004_05. pdf? sequence=1\&isAllowed=y [2 Mar 2019].

Layne, P. (2006) AdvanceVT annual report: Year 3: September 2005-August 2006, [Online], Available: https:/vtechworks.lib.vt.edu/bitstream/handle/10919/72158/advancevt annual report 2005 06. pdf? sequence=1 \&isAllowed-y [2 Mar 2019].

Martin, C.L. (2011) Gender differences in career satisfaction among postsecondary faculty in STEM disciplines. $\mathrm{PhD}$ thesis. The University of Memphis.

National Research Council (2010) Gender differences at critical transitions in the careers of science, engineering, and mathematics faculty. National Academies Press, [Online], Available: https://sites. nationalacademies.org/cs/groups/pgasite/documents/webpage/pga_161620.pdf [1 Mar 2019].

Rancourt, D. (2010) 'Leading your research enterprise - part 2', The Post: Your Newsletter, vol. 1, no. 2, pp. 9-10, University of Calgary.

Reis, R.M. (1997) Tomorrow's professor: Preparing for academic careers in science and engineering, IEEE Press Marketing.

Robst, J., VanGilder, J. and Polachek, S. (2003) 'Perceptions of female faculty treatment in higher education: Which institutions treat women more fairly?', Economics of Education Review, vol. 22, no. 1, pp. 59-67. http:/dx. doi.org/10.1016/S0272-7757(01)00056-5

Rosser, V.J. (2004) 'Faculty members' intentions to leave: A national study on their worklife and satisfaction', Research in Higher Education, vol. 45, no. 3, pp. 285-309. http://dx.doi.org/10.1023/ B:RIHE.0000019591.74425.f1

Stamarski, C.S. and Son Hing, L.S. (2015) 'Gender inequalities in the workplace: The effects of organizational structures, processes, practices, and decision makers' sexism', Frontiers in Psychology, vol. 6. http://dx.doi.org/10.3389/fpsyg.2015.01400

Tabachnick, B.G. and Fidell, L.S. (2013) Using multivariate statistics (6th ed.), Boston, MA: Pearson. University of Virginia (2014) Analysis of start-up package equity among men and women in STEM and SBE fields at the University of Virginia, NSF ADVANCE annual report project Year 2, June 1, 2014, [Online], Available: http:/www advance-virginia.edu/images/2014-Start-up-Package-Study.pdf [2 Mar 2019].

Van Delinder, J., Deng, S., Verchot, J., Madewell, A. and Delano, D. (2015) 'FORWARD Oklahoma State University: Building an academic toolkit for women at a land-grant institution', in Heller, R.S., Mavriplis, C. and Sabila, P.S. (2015) FORWARD to Professorship in STEM: Inclusive Faculty Development Strategies that Work, London, UK: Academic Press is an imprint of Elsevier. 